\title{
Full Scale Compartment Fire Test with Lubricant Oil (Lubricant Oil Fire Test: Part 2)
}

\section{FUJIZUKA}

Mitsubishi Heavy Industries, Ltd. (Mitsubishi Atomic Power Industries, Inc.) 4-1, Shibakouen 2-chome, Minato-ku, Tokyo, Japan

\section{Y. SOUTOME}

Hitachi Works of Hitachi, Ltd.

3-1-1, Saiwaicho, Hitachi, Ibaraki-Pref., Japan

\section{Y. KABASAWA}

Chubu Electric Power Company, Inc.

1, Toushincho, Higashi-ku, Nagoya, Japan

\section{J. MORITA}

Toshiba Corporation

8, Shinsugita, Isogo-ku, Yokahama, Japan

\section{ABSTRACT}

The objective of the tests was to provide the data for use in evaluating the environmental effects of lubricant oil fires in the compartment. Fifty-one tests were conducted to research the environmental effects (atmospheric temperature, radiation heat flux and so forth) on the surroundings with the various size fuel pans and compartments and the various air exchange rates. The concentration of the smoke and $C O$ were also measured in the tests. Test results showed that the radiation heat flux from the high temperature gas and soots was greater than that from the flame because the later was interrupted by the smoke. The gradients of atmospheric temperature were hardly observed in the horizontal. temperature distribution but were observed in the vertical temperature distribution in the compartment. It appeared that the concentrations of smoke and $C O$ were able to be estimated from the ratio of burning rate and air supply rate. From the test results, we have developed a conventional and conservative method to evaluate the environmental effects of lubricant oil fire in the compartment.

\section{INTRODUCTION}

It seems that the lubricant oil fires may at times occur in an industiial plant facilities. Therefore, fire protection on lubricant oil fire shall be taken into consideration in planning the fire protection program of the industrial plant. In this consideration, we conducted the full scale compartment fire tests with turbine oil. The objective of the tests was to research the thermal influences (ex; radiation heat flux, atmospheric temperature and so forth) to the surroundings and the atmospheric condition (ex; smoke and co concentration) in the compartment. preliminary fire tests preceding this test were conducted to get the fundamental data on lubricant oil fire and to obtain necessary data to decide the test condition. (See Reference 1.)

TEST METHOD

Test Condition

Fue 1 source Fuel sources was lubricant oil (Turbine oil VG32) contained in circular pans. The size of the fuel pans were $0.1 \mathrm{~m}^{2}, 0.3 \mathrm{~m}^{2}, 0.5 \mathrm{~m}^{2}, 1.0 \mathrm{~m}^{2}$ and $2.0 \mathrm{~m}^{2}$. 
Test Models Rectangular parallel-piped compartment were used in these tests. The internal dimensions of the compartment were $6.0 \mathrm{~m}$ width, 5. Om height. The length was variable to $3.5 \mathrm{~m}, 7.0 \mathrm{~m}, 10.5 \mathrm{~m}$ and $14.0 \mathrm{~m}$. Fox the additional case, the compartment with the internal dimensions $20 \mathrm{~m}$ length, $8.0 \mathrm{~m}$ width and $5.0 \mathrm{~m}$ height was also used. The walls of the compartment were constructed with fire resistant insulation board (calcium silicate plate) of $25 \mathrm{~mm}$ thickness. Test models are shown in Table-1.

Table-1 List of the test models

Total: 51. models

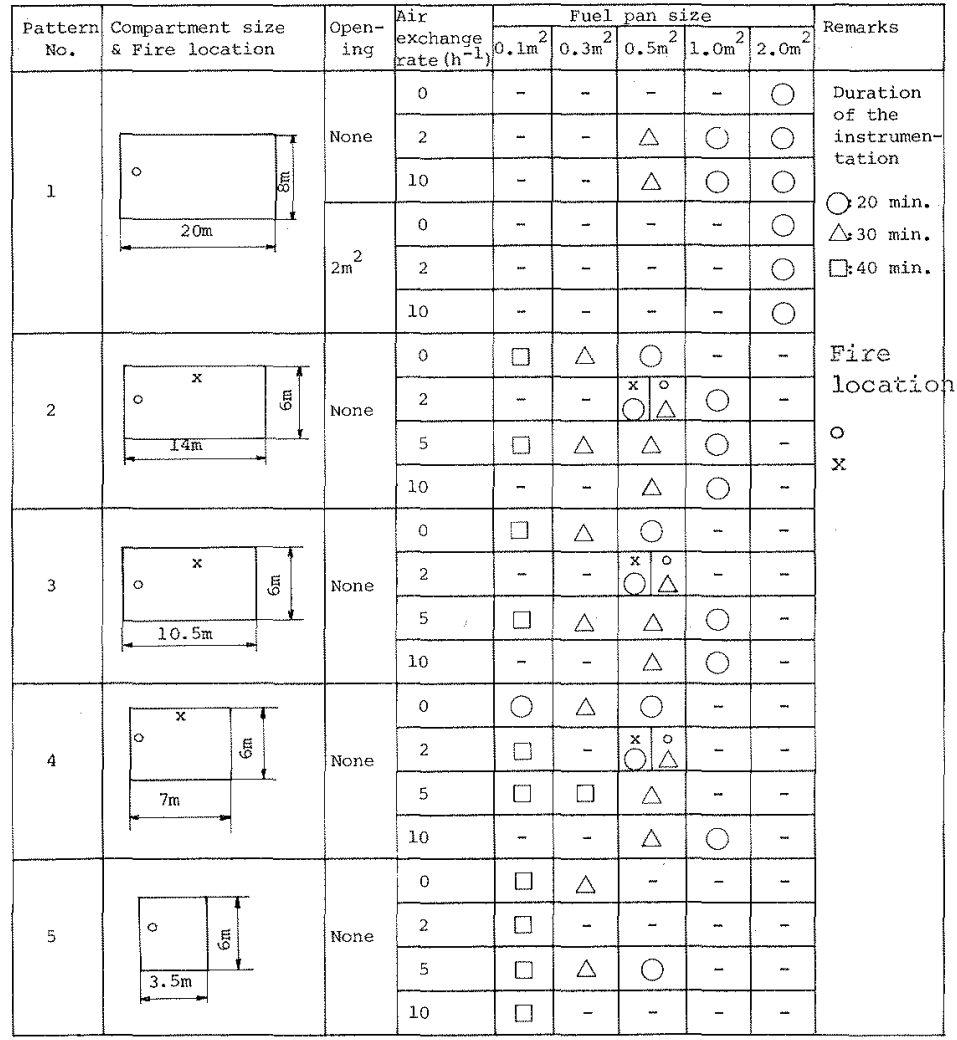

Ventilation Forced ventilation system (push-pull type) was provided to the compartment as shown in Fig. -1 .

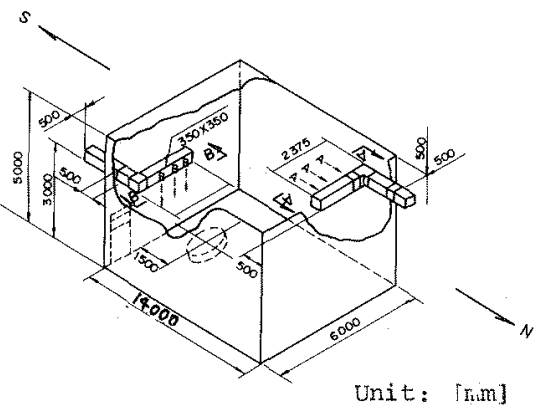

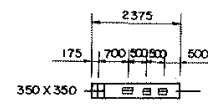

A-A Section

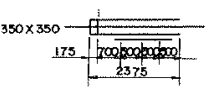

B-B Section

Fig. -1 Configuration of the Compartment model 
Fire location The center of the oil pan was located on the north-south centerline of the room and $1.5 \mathrm{~m}$ away from the south wall.

Location of the instrumentation The location of the instrumentation are shown in Fig. -2 .
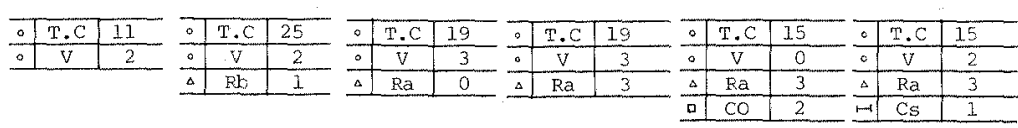

Exhaust Dust

\begin{tabular}{|c|c|}
\hline T.C & 2 \\
\hline $\mathrm{V}$ & 1 \\
\hline $\mathrm{Cs}$ & 1 \\
\hline
\end{tabular}

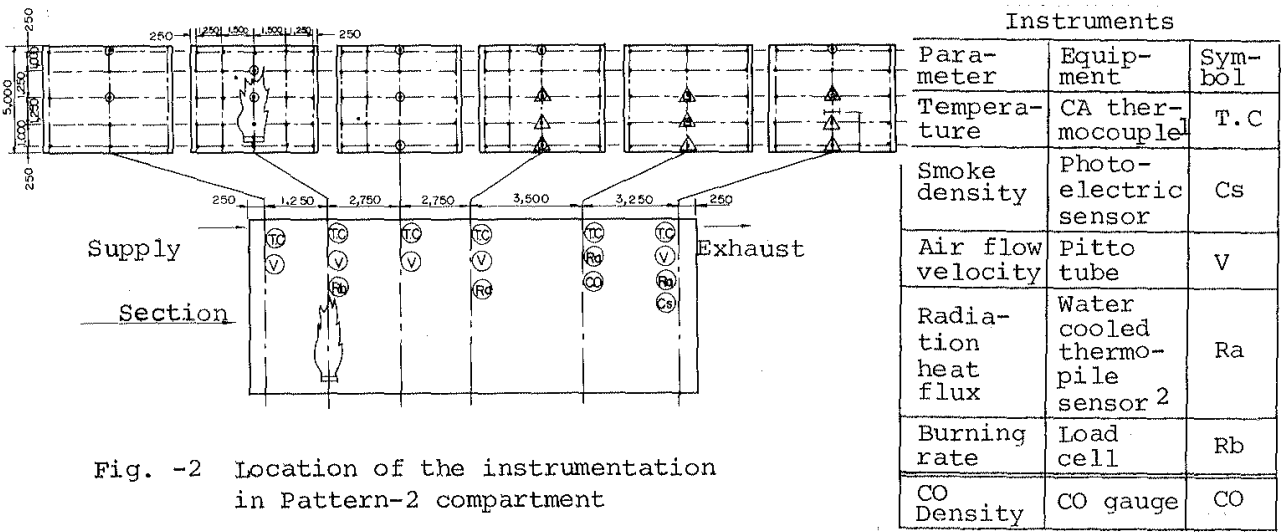

Test Procedure

Pan was filled with turbine oil to the adequate depth according to the duration of an experiment and the gasoline was floated on the surface. It was set on fire by a little gun powder. After ignited, atmospheric temperature, smoke density, aix flow velocity, radiant heat flux, co density and so forth were measured.

\section{TEST RESULTS AND CONSIDERATIONS}

\section{Burning Rate}

As shown in Fig. -3, lubrication oil burning rate in the compartment fire was nearly constant not relating to the values of parameter " $\beta$ " 3 derived from the compartment volume and air exchange rates. Fig. -4 is the comparison of the burning rates of closed space fires with that of free buming fires (open space fires). (see Reference 1.) It appears that the variability of the burning rates of the compartment fire is similar to that of the open space fires and the burning rates is correlative to the diameter of fuel pan. Considering the above, we reached to the conclusion that we could estimate the burning rates of the compartment fire based on those of open space fire.

\footnotetext{
$I_{\text {Fine thermocouples were used to restrict the ratio of the radiation heat }}$ flux in the measurement to a low degree

${ }^{2}$ Sensors with water jacket were used to restrict the ratio of the convective heat flux in the measurement to a low degree.

${ }^{3} \beta=V(n+1) \quad B:$ Air supply rate $\left(m^{3} / h\right)$

$V:$ Compartment volume $\left(\mathrm{m}^{3}\right)$

$\mathrm{n}$ : Air exchange rate $\left(\mathrm{h}^{-1}\right)$
} 

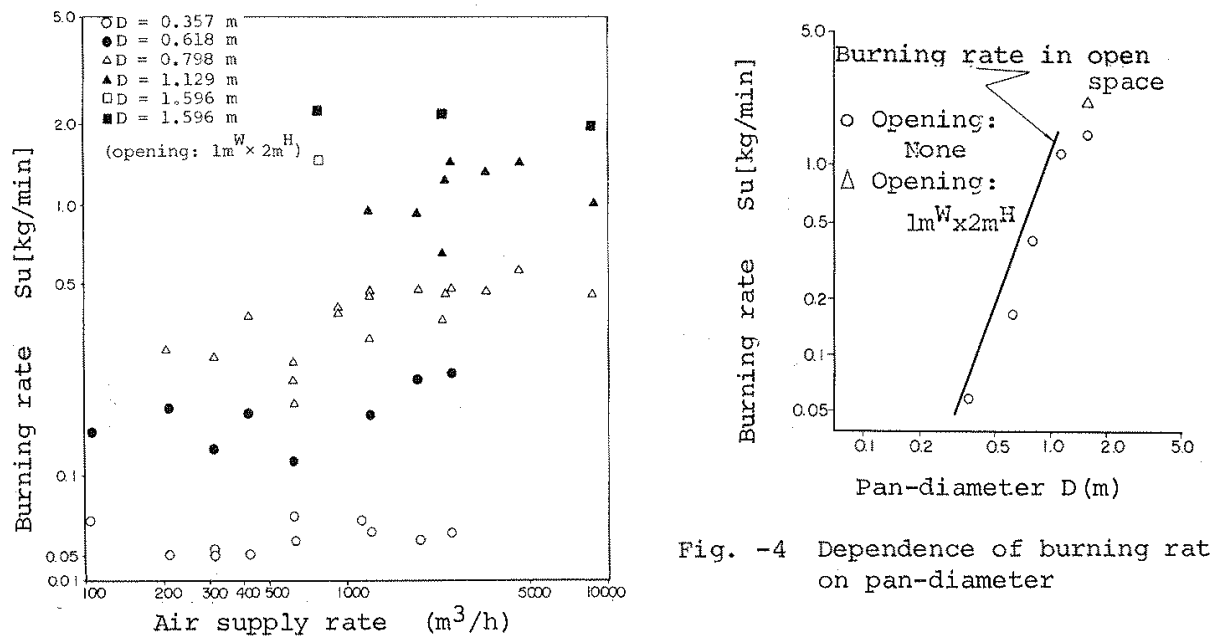

Fig. -4 Dependence of burning rate on pan-diameter

Fig. -3 Dependence of burning rate on air volume

Radiation Heat Flux

As shown in Fia. -5 , received radiation heat flux in the compartment fire was greater than that in the open space fire represented by theory locus curves and the decrease of the received radiation heat flux on the distance was not observed except in the proximity of the fuel pan. This might be because the radiation heat flux from the flame was interrupted by the smoke (gas \& soots) and that from the gas was rather greater than that from the flame.

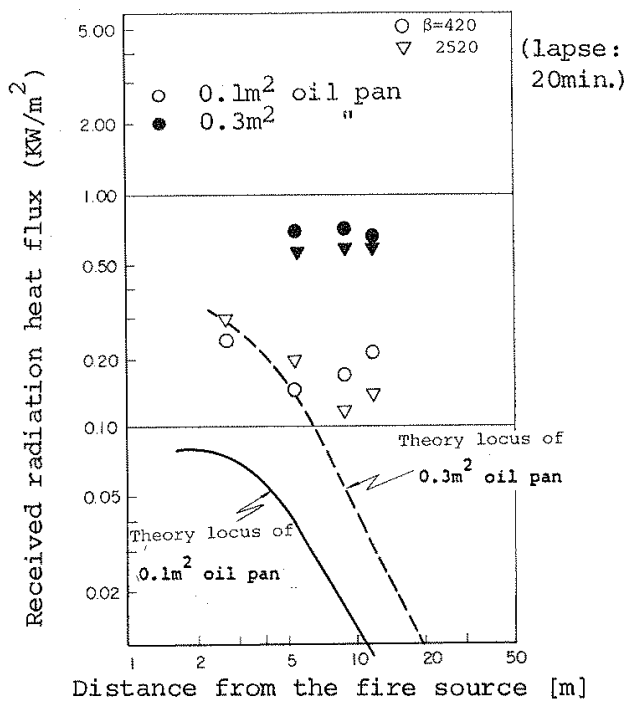

Fig, -5-1 Experimental and predicted received radiation heat flux (Compartment pattern-2 $0.1 \mathrm{~m}^{2} \& 0.3 \mathrm{~m}^{2}$ oi.1 pan)

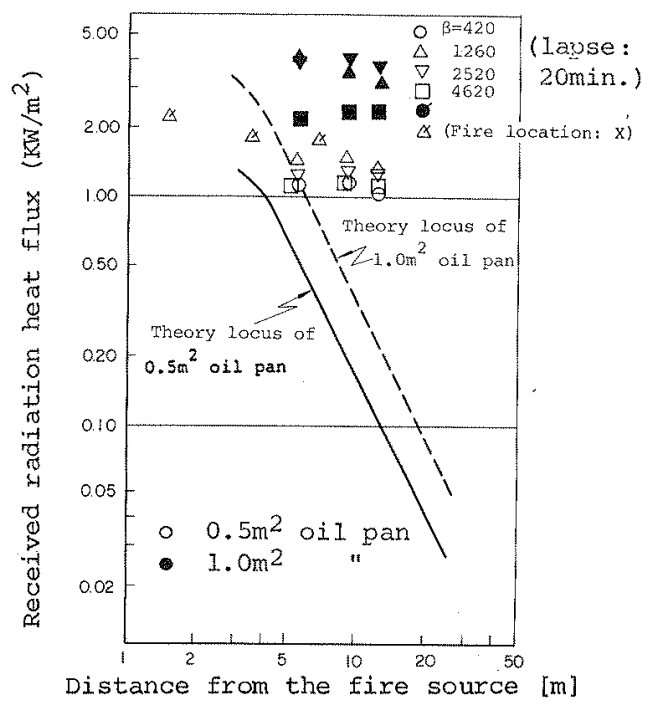

Fig. $-5-2$ Experimental and predicted received radiation heat flux (Compartment pattern-2, $0.5 \mathrm{~m}^{2} \& 1.0 \mathrm{~m}^{2}$ oil pan) 
Fig. -6 shows that the radiation heat flux increases with the increase of gas layer thickness (distance from south wall to receiver) and gas temperature which rises with the lapse of time. In case of small fuel pan, however, radiation heat flux from the flame was greater than the others. This might be because the smoke concentration and gas temperature was low. Considering the above, we studied the radiation heat flux as a function of the gas temperature. The correlation of radiation heat flux and gas temperature is shown in Fig. -7 and -8 .

Experimental estimation formulas were developed from the test data as shown in Table-2. In this table, constant "A" means the product of gas emissivity and Stefan-Boltzmann Constant as follows:

$A=\sigma\left(1-e^{-K \cdot L}\right)$

\section{$\sigma:$ Stefan-Boltzmann Constant \\ K: Gas absorption factor \\ I: Gas layer thickness}

In spite of the formulas being developed, we reached to the conclusion that the radiation heat flux from gas might be estimated from the following formula because of three reasons that follows:

1. The difference of the radiation heat flux due to the distance was smali.

2. The measured values were the limited one because radiation heat flux sensor could not catch the heat flux beyond the angle of elevation $(=2 / 3$ radian).

3. We estimated gas emissivity to the maximum $(=1.0)$. For, we could not estimate the actual gas emissivity because we had not analyzed gas composition in tests.
R: Coefficient of correlation

\begin{tabular}{|c|c|c|c|}
\hline \multicolumn{2}{|c|}{$\begin{array}{l}\text { Distance from } \\
\text { south wall (m) }\end{array}$} & $A \times\left(10^{-11}\right)$ & Remarks \\
\hline 1 & 2.50 & 3.670 & $R=0.116$ \\
\hline 2 & 3.375 & 4.310 & $R=-0.756$ \\
\hline 3 & 3.50 & 3.310 & $R=0.988$ \\
\hline 4 & 4.25 & 4.017 & $R=-0.555$ \\
\hline 5 & 5.25 & 3.313 & $R=0.976$ \\
\hline 6 & 5.75 & 3.083 & 0.991 \\
\hline 7 & 6.75 & 2.894 & 0.950 \\
\hline 8 & 7.00 & 3.509 & 0.981 \\
\hline 9 & 7.875 & 3.710 & 0.987 \\
\hline 10 & 10.0 & 2.807 & 0.973 \\
\hline 11 & 10.25 & 3.395 & 0.983 \\
\hline 12 & 10.4 & 3.455 & 0.984 \\
\hline 13 & 13.75 & 3.514 & 0.990 \\
\hline 74 & 15.0 & 2.663 & 0.967 \\
\hline 15 & 19.75 & 2.858 & $R=0.980$ \\
\hline
\end{tabular}

Table-2 Experimental estimation formulas on received radiation heat flux

$Q x=\sigma\left(\mathrm{T}^{4}-\mathrm{T}_{0}^{4}\right)\left(\mathrm{KW} / \mathrm{m}^{2}\right)$

$\sigma=5.67 \times 10^{-11}\left(\mathrm{KW} /{ }^{\circ} \mathrm{K}^{4} \cdot \mathrm{m}^{2}\right)$ (Stefan-Boltzmann Constant)

Qr: Received gas radiation heat flux $\left(\mathrm{KW} / \mathrm{m}^{2}\right)$

$T$ : Atmospheric temperature ( $\left.{ }^{\circ} \mathrm{K}\right)$

$\mathrm{T}_{\mathrm{O}}$ : Receiver temperature $\left({ }^{\circ} \mathrm{K}\right)$

In the end, we reached to the conclusion that the radiation heat flux in the compartment fire could be estimated conservatively by suming the heat flux values of gas radiation and flame radiation.

\section{Atmospheric Temperature}

As shown in Fig. -9, the gradients of atmospheric temperature were observed in the vertical temperature distribution and were on the increase depending on the increase of fuel pan diameter or the decrease of the air exchange rate. 
Oil pan size

$0.1 \mathrm{~m}^{2}$

$0.3 \mathrm{~m}^{2}$

$0.5 \mathrm{~m}^{2}$
$1.0 \mathrm{~m}^{2}$

Air exchange rate $0 \begin{aligned} & n=0 \\ & n=2\end{aligned}$

$\circlearrowleft \begin{array}{ll}n=2 \\ \bigcirc & n=10\end{array}$

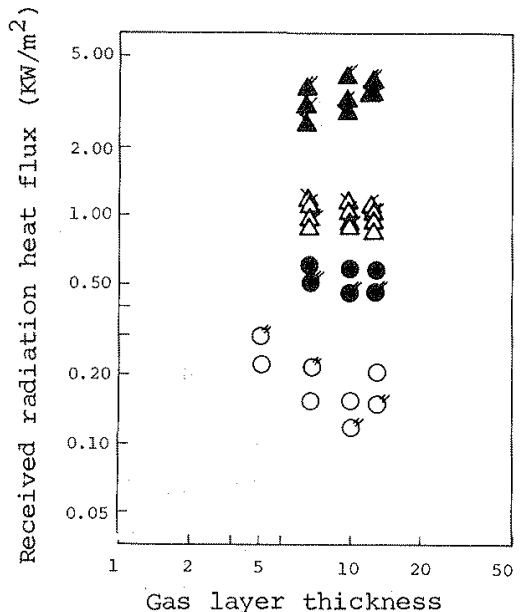

(Distance from the south wall) [m]

Fig. -6-I Dependence of received radiation heat flux on gas layer thickness (1apse: 10min.)

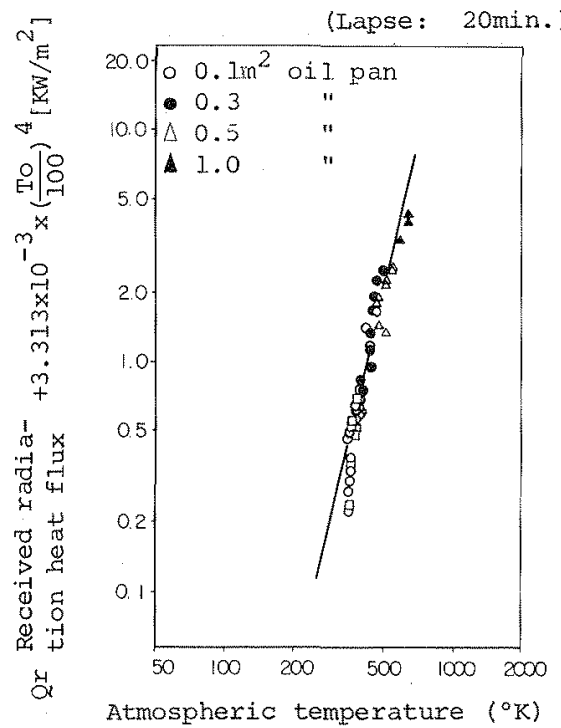

Fig. -7 Radiation heat flux vs. gas temperature (at $6.75 \mathrm{~m}$ against south wall)

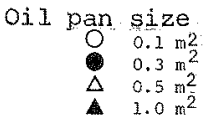

Air exchange rate

$\bigcirc n \neq 0$

$\overbrace{n=5}^{n=2}$

$\bigcirc$

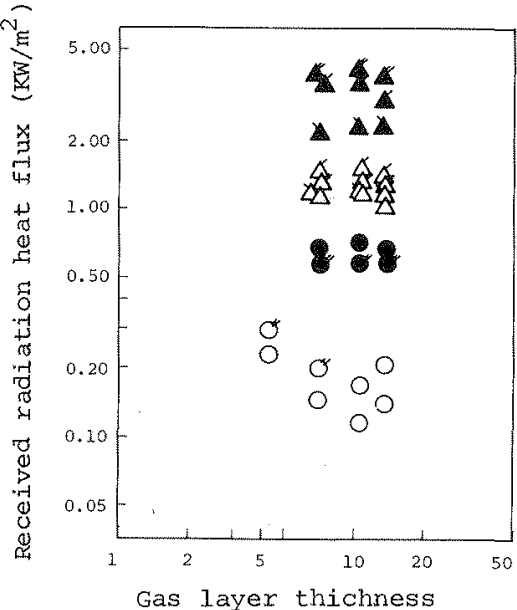

(Distance from the south wall) [m]

Fig. $-6-2$ Dependence of received radiation heat flux on gas layex thickness (1apse: 20min.)
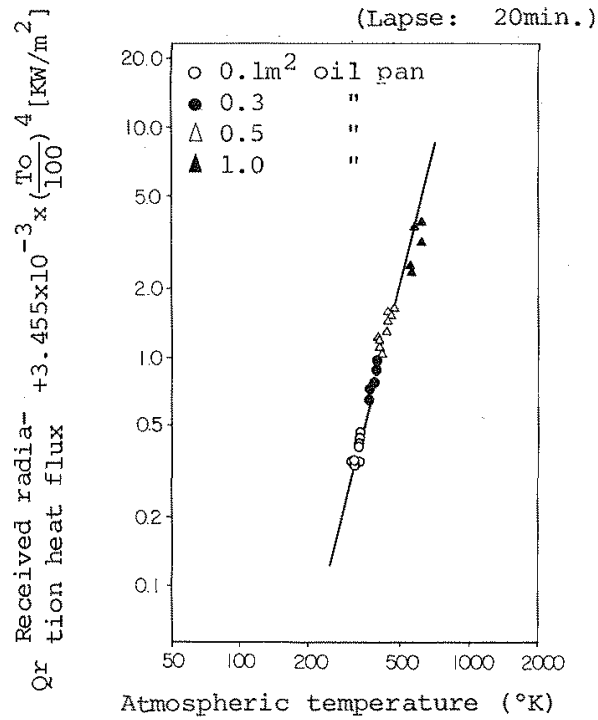

Fig. -8 Radiation heat flux vs. gas temperature

(at $13.75 \mathrm{~m}$ against south wall) 
And the difference due to the fire location was not observed. The gradients of atmospheric temperature were also not observed in the horizontal distribution except just above the fuel pan. That is to say, atmospheric temperature was constant everywhere at the same elevation in the compartment. The correlation of the maximum atmospheric temperature at the same elevation and the parameter " $\alpha$ " is shown in Fig. -10 .

$1_{\alpha}=\frac{V(1+n t)}{s}$
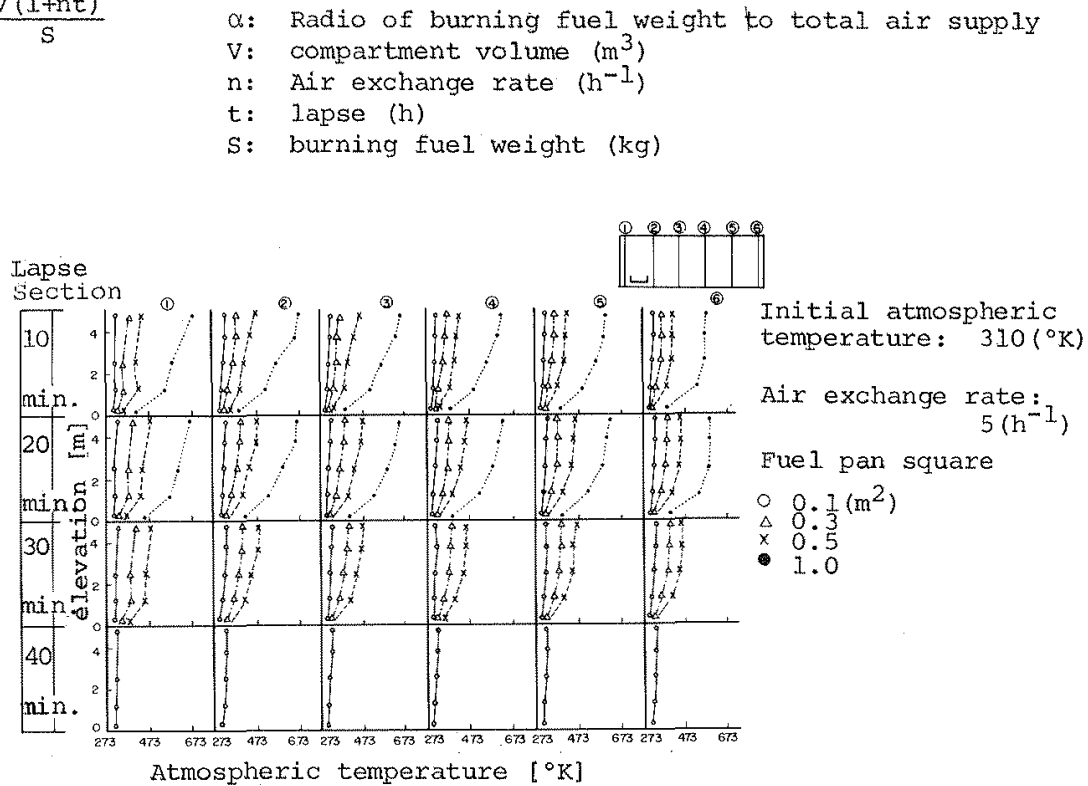

Fig. -9-1 Atmospheric temperature distribution in pattern-2 compartment (Effects of fuel pan size)

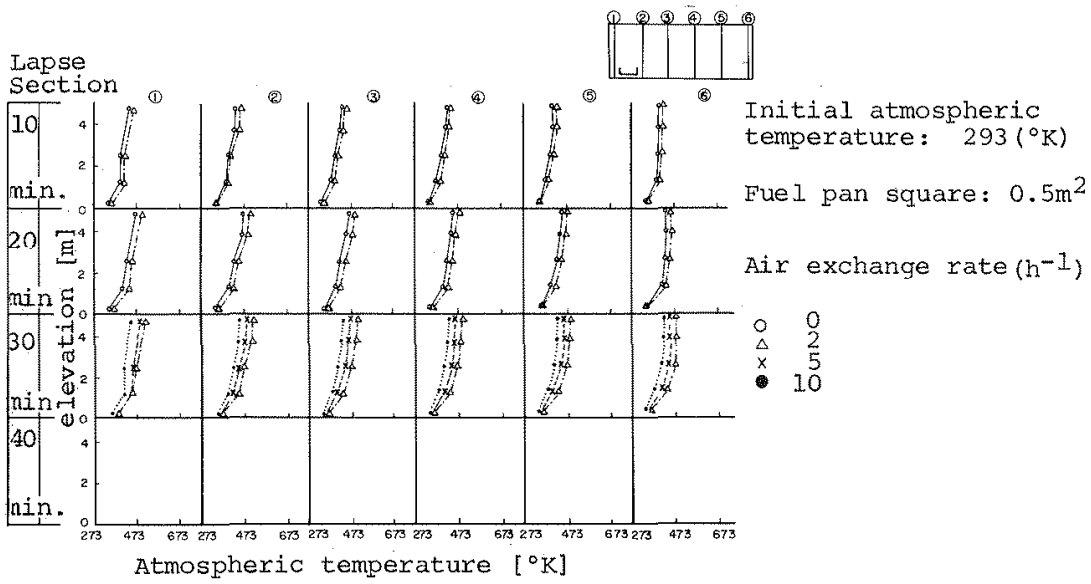

Fig. -9-2 Atmospheric temperature distribution in pattern-2 compartment (Effects of air exchange rate) 


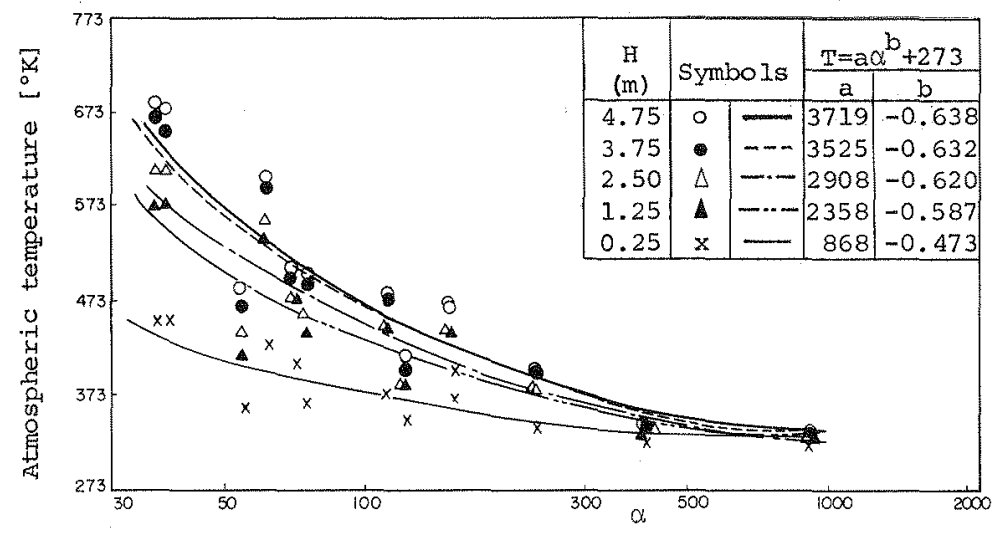

Fig. -10 Correlation of atmospheric temperature (Lapse: 20min.)

In the end, we developed the following formula to estimate the atmospheric temperature of free elevation.

$T=a \alpha^{b}+273$

$$
\begin{aligned}
& a=1344 \cdot h^{0.354} \\
& b=-0.494 \cdot h^{0.0745}
\end{aligned}
$$

$\mathrm{T}:$ Atmospheric temperature $\left({ }^{\circ} \mathrm{K}\right)$

$h$ : Elevation $(m)$

NOTE: This formula is available in case of initial atmospheric temperature being about $293^{\circ} \mathrm{K}$ (=test condition). Difference in initial atmospheric temperature should be taken into consideration in case of estimating the atmospheric temperature in other initial condition.

Smoke

As shown in Fig. -11 , the concentration of the smoke became beyond the measuring limit ( $\mathrm{CS}=5$ ) of the instrument by about 5 minutes. It was observed that the speed of smoke accumulation was very high in the compartment fire. We developed the following experimental formula to estimate the smoke concentra. tion.

$C s=40.57 \cdot \alpha^{-0.485}$

Extinct coefficient: Cs $(1 / \mathrm{m})$

$I=I_{0} \cdot e^{-C s \cdot Q}$

Io: Source illuminance (Lux)

I: Receiver illuminance (Lux)

$\ell$ : Distance from the source to receiver (m)

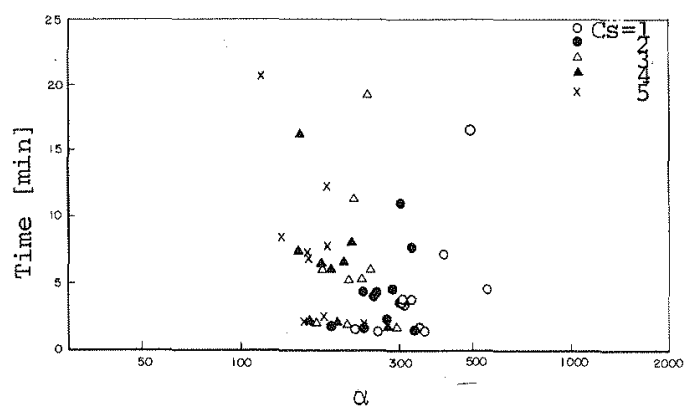

Fig. -11 Dependence of smoke concentration on $\alpha$ 
As shown in Fig. -12, the values of $\mathrm{CO}$ concentration were on the decrease with the increase of parameter " $\alpha$ ". It became to the dangerous concentration for long stay (approximately, 1000 - 3000ppm) in case of parameter " $\alpha$ " being under 100 .

We developed the following experimental formula to estimate the co concentration.
EL: $\quad$ I. $25 \mathrm{M}$
$\mathrm{CO}=3.33 \times 10^{5} \cdot \alpha^{-1.282}$
EL: $\quad 2.50 \mathrm{M}$
$C O=7.16 \times 10^{5} \cdot \alpha^{-1.482}$

Co: CO concentration (ppm)

Air Flow Velocity

As shown in Fig. -i3, the values of air flow velocity were on the decrease with the increase of convection distance.

We developed the following experimental formula to estimate the air flow velocity.

$v=a \cdot x^{-b}$

$a=6.73 \cdot s u^{0.164}$

$\mathrm{b}=0.880 \cdot \mathrm{su}^{-0.0607}$

$\mathrm{V}$ : Air flow velocity (m/s)

$\mathrm{Su}$ : Burning rate $(\mathrm{kg} / \mathrm{min}$.

$\mathrm{x}$ : Convection distance (m)

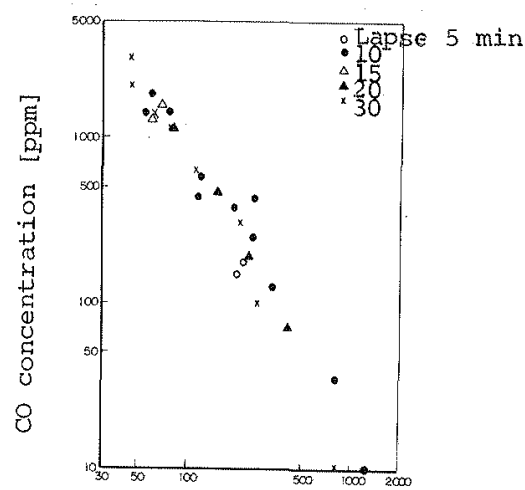

0

Fig. -12 Dependence of co concentration on $\alpha(H=1.25 \mathrm{~m})$

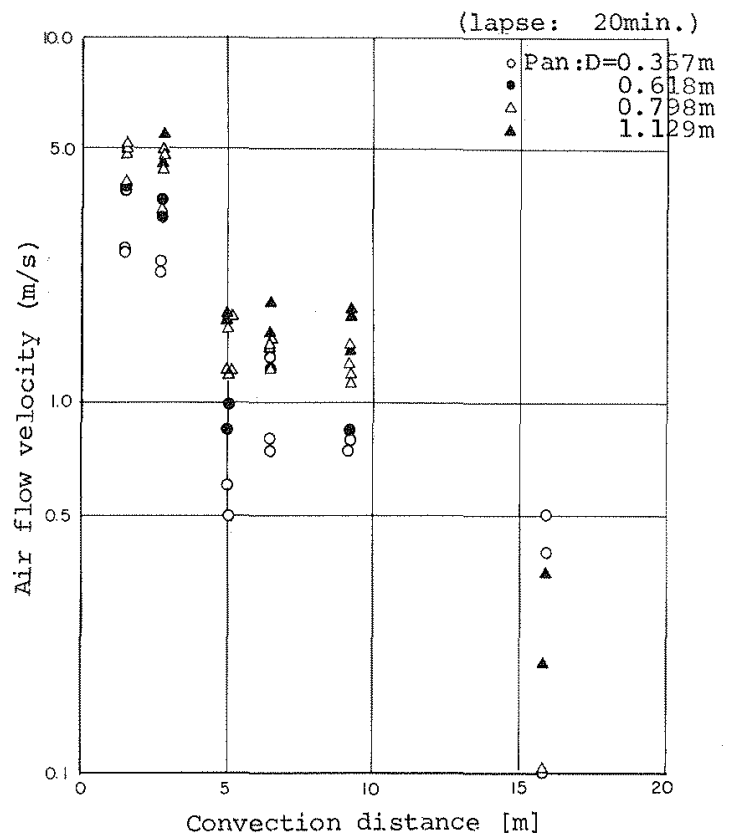

Fig. -13 Dependence of aix flow velocity on convection distance 


\section{CONCLUSION}

We developed the method to estimate the compartment fire behavior conservatively as follows.

(1) The burning rate in the compartment fire can be estimated at that in the open space fire.

(2) The radiation heat flux can be estimated at the sum of heat flux values of gas radiation and flame radiation.

(3) Atmospheric temperature can be estimated depending on the following formula.
$\mathrm{T}=\mathrm{a} \cdot \alpha^{\mathrm{b}}+273\left({ }^{\circ} \mathrm{K}\right)$
$a=1344 \cdot h^{0.354}$
$\mathrm{b}=-0.494 \cdot \mathrm{h}^{0.0745}$

(4) Concentration of the smoke can be estimated depending on the following formula

$\mathrm{cs}=40.47 \cdot \alpha^{-0.485}(1 / \mathrm{m})$

(5) Concentration of the $\mathrm{CO}$ can be estimated depending on the following formula.

$$
\begin{array}{llll}
\mathrm{CO}=3.33 \times 10^{5} \cdot \alpha^{-1.282} & (\mathrm{ppm}) & (\mathrm{EL}: & 1.25 \mathrm{M}) \\
\mathrm{CO}=7.16 \times 10^{5} \cdot \alpha^{1.482} & (\mathrm{ppm}) & (\mathrm{EL}: 2.50 \mathrm{M})
\end{array}
$$

(6) Air velocity of convection flow can be estimated depending on the following formula.

$$
\begin{aligned}
& \mathrm{v}=\mathrm{a} \cdot \mathrm{x}^{-\mathrm{b}}(\mathrm{m} / \mathrm{s}) \quad \mathrm{a}=6.73 \cdot \mathrm{su}^{0.164} \\
& \mathrm{~b}=0.88 \cdot \mathrm{su}^{-0.0607}
\end{aligned}
$$

\section{ACKNOWLEDGEMENT}

The tests were conducted by the joint study of the following companies.

Chubu Electric Power Company, Inc.; The Hokkaido Electric Power Company, Inc.; Tohoku Electric Power Company, Inc.; Tokyo Electric Power Company, Inc.; The Hokuriku Electric Power Company, Inc.; The Kansai Electric Power Company, Inc.; The Chugoku Electric Power Company, Inc.; Shikoku Electric Power Company, Inc, ; The Kyushu Electric Power Company, Inc.; The Japan Atomic Power Company; Mitsubishi Heavy Industries, Ltd.; Toshiba Corporation; Hitachi, Itd.

The authors wish to thank many technical and engineering staff in conducting the tests, and especially emeritus Prof. S. Hoshino (University of Tokyo), emeritus Prof. H. Saito (University of Tokyo) and Prof. Y. Uehara (Yokohama National University) for the valuable advices.

\section{REF'ERENCE}

1. T. Tanaka, Y. Kobasawa, Y. Soutome and M. Fujizuka: "Preliminary Test for Ful1 Scale Compartment Fire Test (Lubricant Oil Fire Test; Part-1)," First International Symposium on Fire Safety Science, 1985 